\title{
Do Age and Gender Have Anything to Do with Job Satisfaction: A Practical Outlook on the Nigerian Public Sector
}

\author{
Manasseh N. Iroegbu \\ Department of Psychology, Faculty of Social Sciences, University of Uyo, Uyo, Nigeria
}

Email address:

manassehiroegbu@yahoo.com

To cite this article:

Manasseh N. Iroegbu. Do Age and Gender Have Anything to Do with Job Satisfaction: A Practical Outlook on the Nigerian Public Sector. American Journal of Applied Psychology. Vol. 4, No. 4, 2015, pp. 111-114. doi: 10.11648/j.ajap.20150404.15

\begin{abstract}
This research examined the influence of gender and age on job satisfaction among employees working in the public service of Nigeria. 3000 participants from the head quarters of Nigeria's federal service were randomly chosen for the study. Participants were dichotomized into 1620 males and 1380 females, 1590 older employees and 1410 younger employees. The instrument used for the study was the Minnesota Satisfaction Questionnaire ( $r=0.89)$. The design employed was the $2 \times 2$ factorial design while the two way ANOVA was used for data analysis. The results of the study revealed that the female employees experienced a higher level of job satisfaction than the male employees. Furthermore, the older employees of 45 years and above experienced a higher job satisfaction than the younger employees of 20 years and above. There was no significant interaction between age and gender. The implication of this finding is that the expectation of male workers from the organization seem to be higher than that of the females as a result of their heavy financial obligations to their immediate and extended families in line with the African culture. Also, older employees were more satisfied because their long stay had attracted many benefits which younger employees could not obtain.
\end{abstract}

Keywords: Job Satisfaction, Motivation, Gender, Age, Public Sector Organisation

\section{Introduction}

The job satisfaction of workers in Nigeria has been a reoccurring issue over the years. The lack of job satisfaction has led to many strike actions undertaken at various times by wide spread sections otf the Nigerian economy for many diverse reasons ranging from pay to several other factors. Maslow (1943) observed that man in industry is just as complex as man in any other phase of life and that any attempt to reduce his behavior to a single system of motivation and satisfaction must result in artificiality and narrowness. Man has many motives and unless we recognize the parts played by each one, we cannot possibly begin to understand his behavior (Maslow 1943). The theoretical framework for this study was therefore based on Maslow (1943) motivation theory of job satisfaction which stipulated the existence of a hierarchy of needs which all employees seek to satisfy at work. However, whereas these needs are enormous and diverse, the strength and hierarchy of the desires for their satisfaction naturally differs and it's not the same for all individuals, but influenced by their age range(whether young or elderly) as well as by their gender(whether male or female). Thus, employees desire different things at different times as a function of their respective age and gender, and the capacity of the organization to satisfy these various needs is what engenders the workers motivation.

Due to the high level of unemployment in Nigeria, employers of labor have begun to lay emphasis on age and gender as parameters and indices for hiring workers. In some sectors, females are usually more preferred than males while in general, younger people are preferred more than older ones. While there is no open policy or law in these respects, observations have shown that this is the practice in many places in Nigeria. It is against this background that a need to understand how and if age and gender are predominant factors in the job satisfaction of Nigerian workers becomes very imperative. More so, the exploration of these variables in the Nigerian context has not been given much attention as many researchers had concentrated on pay and working conditions.

The literature on the impact of age and gender on job 
satisfaction has been varied. Frances Burks (2015) observed from a study entitled "what is the relationship between job satisfaction and age", that age as a factor affects job satisfaction. According to him, some job surveys indicated that older workers are more satisfied with their jobs than younger workers. The higher job satisfaction among older employees may be due to the perks that come with maintaining a long career, including higher salaries, better benefits and success in the work place.

Boumans et al (2011) studied age differences in work motivation and job satisfaction: the influence of age on the relationships between work characteristics and workers outcomes. 1036 workers of a Dutch multinational organization were used in the study. The results indicated that the positive correlation between motivating potential scores and motivation was stronger for older than for younger employees. The conclusion therefore, was that older employees seemed to be more satisfied intrinsically with their jobs than younger employees

Sadegh Rast and Azardeh Tourani (2013) carried out a study on evaluation of employee's job satisfaction and role of gender differences: An empirical study at an airline industry in Iran. The purpose of the study was to discover the level of employee's job satisfaction and to investigate the effect of gender on employee job satisfaction. Data was collected from employees of three private airline companies in Iran, and a ttest was used to test the relationship between employee job satisfaction and their gender. Findings suggested that there was no significant difference between male and female employees' job satisfaction.

Cesar Carrillo Garcia et al (2013) studied job satisfaction among health care workers: the role of gender and age. 546 professionals in a university hospital were sampled using NTP job satisfaction scale. Result showed overwhelming evidence of feminization of practically all health care professions included in the study with a higher level of job satisfaction among women than men. Regarding age, 20-30 years old and professions over 61 years old showed higher satisfaction levels than the middle aged of 41-50 years.

Al-Ajmi, Rashed (2006) studied the effect of gender on job satisfaction and organizational commitment in Kuwait. Data was collected from 436 employees (213 female and 223 males) drawn from government ministries. Correlation and one way ANOVA were employed in data analysis. Results indicated that there were no significant differences between the male and females in job satisfaction i.e. no gender differences were found.

Kwangho Jung et al (2013), studied how age, gender and sector affect job satisfaction:? Results from the Korea labour and income panel data. Samples for the study were drawn from the Korean public and private service. Result showed that no substantial difference was found in the job satisfaction of public employees of different ages, but a negative association was found in a sub sample of private employees. The study further showed that there was a gender effect on job satisfaction.

Ngozi Sydney Agbor et al (2014) studied the influence of emotional intelligence and gender on job satisfaction among local government employees. 160 employees from Owerri and Oguta municipal councils in Nigeria were drawn for the study and analysis was carried out with a two way ANOVA. The results revealed that gender had no effect on job satisfaction. Also, no interaction effect was found between the variables.

Glen D. Moyes et al (2006) studied the effect of age and gender upon the perceptions of accounting professionals concerning their job satisfaction and work related attributes. 245 participants were sampled from accounting professionals. The questionnaire was designed with a six point likert scale to give a measure of the respondents' perception about their job satisfaction. The findings of the study revealed that the work related attributes of job satisfaction were significant to age and gender.

Md. Shanim Hossain (2014) studied job satisfaction of bank employees iqn Bangladesh. The study sampled workers employed in the public and private banks in Bangladesh. A questionnaire instrument was used to tap information on the bankers' job satisfaction, age and gender. The study showed that individual factors such as age and gender did not significantly influence employee job satisfaction in the banks.

\subsection{Statement of the Problem}

In the light of inconsistencies in research findings, and the dearth of research in this area among Nigerian workers, the study seeks to uncover whether age and gender play important roles in the understanding of the issue of job satisfaction in Nigeria. The purpose and contribution of this study was not only to clear the inconsistencies in research, but also to make organizations draw lessons that will help them to plan adequately for the needs and motivation of their employees based on their age and gender differences.

\subsection{Hypothesis}

$\mathrm{H}_{1}$ : The female gender will show a statistically significant higher job satisfaction than the male gender.

$\mathrm{H}_{2}$ : The older employees of 45 years and above will show a statistically significant higher job satisfaction than the younger employees of 20years and above.

\section{Methodology}

\subsection{Participants}

The subjects for this study were 3000 workers sampled from the Federal Secretariat Abuja, the center and the Head Quarters of the Nigerian public service. They were chosen via simple random sampling. Their age range was between 20-65 years. The 3000 workers were made up of 1620 females and 1380 males; 1590 older employees (45-65 years) and 1410 younger employees (20-44 years).

\subsection{Instrument}

The Minnesota Satisfaction Questionnaire (MSQ) was 
used for the study. The scale has 20 items on a 5 point likert scale with responses ranging from 1 (very satisfied) to 5 (very dissatisfied). The minimum and maximum scores were 20 and 100. A low score indicated high job satisfaction while a high score indicated low job satisfaction. The test-retest reliabilities were 0.89 over one week and 0.70 over one year, internal consistency: 0.84-0.91. The MSQ is a self administered questionnaire with a five minute administration time frame.

\subsection{Procedure}

The simple random sampling technique of Yes/No was used to select the 3000 workers. All those who picked yes' were selected into the sample. The MSQ which test duration was 5 minutes was promptly administered. Participants were assured of their confidentiality and so, no ethical issues were involved as they all consented.

\subsection{Design}

The study utilized a $2 \times 2$ factorial design to allow for the examination of separate effects of the independent variables (age and gender) and the interaction effects of both variables on Job satisfaction.

\subsection{Statistics}

The two way analysis of variance (ANOVA) was used for data analysis while the F-test was used for the interpretation of results.

\section{Results}

Table 1. 2x2 Anova Summary Table of the Impact of Age and Gender on Job Satisfaction.

\begin{tabular}{llllll}
\hline SOV & SS & DF & MS & F & P \\
\hline A(Gender) & 139001 & 1 & 139001 & 167 & $\begin{array}{l}<.05 \text { (Signifi } \\
\text { cant) } \\
\end{array}$ \\
B(Age) & 107010 & 1 & 107010 & 129.9 & $\begin{array}{l}<.05 \text { (Signifi } \\
\text { cant) }\end{array}$ \\
$\begin{array}{l}\text { AB(Age/Gender } \\
\text { interactions) }\end{array}$ & 2011 & 1 & 2011 & 2.42 & $\begin{array}{l}>.05 \text { (Not } \\
\text { s/AB (Error) }\end{array}$ \\
$\begin{array}{l}\text { Sum } \\
\text { Sumificant) }\end{array}$ & 495961 & 2996 & 830 & & \\
\hline
\end{tabular}

The results presented in table 1 indicated that the influence of gender (variable A) on job satisfaction was statistically significant $[F(1,2996)=167, p<0.05)$. That is to say that the mean of the female gender $(\mathrm{X}=63)$ was lower than that of the male gender $(\mathrm{X}=75.5)$. Therefore, the hypothesis $\left(\mathrm{H}_{1}\right)$ which stated that the female gender will show a statistically significant higher satisfaction than the male gender was accepted.

Furthermore, the results indicated that the influence of age (variable B) on job satisfaction was statistically significant. $[\mathrm{F}(1,2996)=129, \mathrm{P}<0.05]$. That meant that, the mean of the younger employees $(X=75)$ exceeded that of the older employees $(\mathrm{X}=64)$. Therefore, the second Hypothesis $\left(\mathrm{H}_{2}\right)$ which stated that the older employees of 45 years and above will show a statistically significant higher job satisfaction than the younger employees of 20 years and above was accepted. Thirdly, there was no interaction effects found between age and gender on job satisfaction. $[\mathrm{F}(1,2996)=2.42$, $\mathrm{P}>0.05]$

\section{Discussion}

The findings of this study in relation to gender have shown that the female gender experienced a higher job satisfaction in their jobs than the male gender. This result is in consonance with the findings of Cesar Garcia et al (2013) and Glen D. Moyes et al (2006) who discovered that the females in their samples had a higher level of job satisfaction than their male counterparts. The reason for this finding in Nigeria could be as a result of the fact that the male gender are the bread winners of the families by culture and so a lot of responsibilities are shouldered by them, unlike the women folk. Due to the fact that their financial responsibilities are enormous, their expectations from the job are usually higher than that of the females, and the inability of the public service to meet these expectations led to reduced job satisfaction. That may explain why strike actions in Nigeria were always spear headed by male workers rather than the female employees.

Furthermore, the findings of this study in relation to age have shown that older employees of 45 years and above experienced a higher job satisfaction than the younger employees. The finding is in line with the findings of Boumans, N.P et al (2011) and Francis Burks (2015). The reason for this finding might be that older employees have reached the establishment stage in their career and would not want to jump from one job to another in order not to loose the huge retirement benefits that will accrue to them, and that may be why they were more satisfied than the younger workers.

In addition, older workers, due to their long stay occupy sensitive and managerial positions in the organizations and by implication enjoy better pay and allowances. Therefore, the trend in Nigeria whereby organizations prefer to hire younger employees than older ones may have little to do with job satisfaction but more to do with the work energies that abound in younger employees and starting pay which will not be as high as that demanded by older and more experienced employees. Also the younger employees are in the exploratory stage of their careers and have opportunities of moving from one organization to another over a time.

\section{Conclusion}

The findings of this research have shown that gender and age are also critical factors in the exploration of job satisfaction of employees in any organization. It is not enough for organizations to dwell only on pay and working conditions because that may not only provide the solutions to the job satisfaction of her workers and an enhanced work force. 


\section{References}

[1] Al-Ajmi, Rashed (2006). The Effect of Gender on Job Satisfaction and Organisational Commitment in Kuwait. International Journal of Management, Vol. 23, No.4.

[2] Boumans, N.P. et al (2011) Age Differences in Work Motivation and Job Satisfaction: The Influence of Age on the Relationship between Work Characteristics and Workers Outcomes. International Journal of Aging Human Development. www.ncbi.nim.nih.gov.pubmed.22474915.

[3] Cesar Carillo Garcia, Maria del Carmen, Solano Ruz, M.E. Martinez, Carmen I.G. Garcia (2013) Job Satisfaction Among Health Workers: The Role of Gender and Age. Latimo-Am. Enfermagen Vol. 21. N0 6.

[4] Frances Burks (2015). What is the Relationship between Job Satisfaction and Age. Demand media smallbusiness.chron.com/relationship.

[5] Glen D. Moyes, P.A. Williams and Bruce Koch (2006). The Effects of Age and Gender on the Perceptions of Accounting
Professionals Concerning their Satisfactions and Job related Attributes.Managerial Auditing Journal.Vol.21(5) pp 536-561

[6] Kwangho Jung, M. Jae Moon, Sung Duek Hahm (2013). Do Age Gender and Sector Affect Job Satisfaction? Results From the Korean Labor and Income Panel Data. rop.sagepub.com/content/27/2/125.short.

[7] Maslow, A.H. (1943) A theory of Human Motivation. Motivation and Personality. New York. Harper \& Row.

[8] Md. Shanim Hossain (2014). Job Satisfaction of Bank Employees in Bangladesh. Social Science Research Network. http://ssrn.com/abstract.

[9] Ngozi Sydney Agbor, R.E. Ebeh, B.E. Nwankwo and S.A. Agu (2014). Influence of Emotional Intelligence and Gender on Job Satisfaction Among Local Gorvernment Employees. Research in Psychology and Behavioral Sciences (RPBS), 2(4) PP 86-89

[10] Sadegh Rast and Azadeh Tourani (2013). Evaluation of Employees Job Satisfaction and Role of Gender Difference: An Empirical Study at an Airline Industry in Iran. www.academia.edu/1471852/Evaluation.ijbssnot.com 